\author{
Associate professor Yang LIN, PhD \\ E-mail:linyang42@163.com \\ School of Economics, Fujian Normal University \\ Associate professor Wen-li LIU, PhD \\ E-mail:liuwenli28@126.com \\ Professor Ying-Ming WANG, PhD \\ E-mail:msymwang@hotmail.com \\ Decision Sciences Institute, Fuzhou University
}

\title{
AN INTEGRATED APPROACH USING CROSS-EFFICIENCY AND SHAPLEY VALUE IN PERFORMANCE EVALUATION
}

\begin{abstract}
Ranking decision making units (DMUs) for performance evaluation is an important issue in data envelopment analysis (DEA). This paper develops an integrated approach for ranking DMUs in DEA cooperative game, where DMUs are evaluated according to their Shapley values. For this purpose, a new characteristic function with DMUs is firstly defined; then, both aggressive and benevolent model formulations, which corresponding to aggressive or benevolent strategy in cooperative game, are utilized to obtain cross-efficiency scores of DMUs. Subsequently, the Shapley values are calculated in terms of the cross-efficiency scores by a simple formulation. An empirical study concerning assessment of nine container ports in China is examined using the developed approach. Comparisons and analyses with previous similar methods are also discussed.
\end{abstract}

Keywords: data envelopment analysis, cross efficiency, cooperative game, Shapley value, performance evaluation.

\section{JEL Classification: O570, P270}

\section{Introduction}

As a practical methodology for assessing performance of DMUs, data envelopment analysis (DEA) utilizes multiple inputs to produce multiple outputs without parametric assumptions (Charnes et al. 1978). DEA does not demand prior information about the relationship during multiple performance evaluations, yet traditional DEA models are not very appropriate in ranking DMUs since they are identified as either efficient or inefficient (Wu et al. 2009a). To overcome this flaw, 
Yang Lin,Wen-li Liu, Ying-Ming Wang

cross-efficiency evaluation (CEE) has been proposed by Sexton et al. (1986) as a DEA extension tool, which considering both self-evaluated and peer-evaluated efficiency scores.

Owing to its discriminability, CEE has been widely applied in relative efficiency assessments in DEA literature. However, it is argued that CEE still suffers from a non-uniqueness of efficiency scores due to the possible existence of multiple optimal weights (Wang et al. 2011, Wu et al. 2016). Several alternative approaches such as aggressive/benevolent secondary formulation (Doyle and Green 1994, 1995), DEA game model (Liang et al. 2008), neutral DEA model (Wang and Chin 2010) and weight-balanced model (Wu et al. 2012) have since been suggested.

In recent years, cooperative game theory has increasingly been combined with DEA technique for evaluating performance of DMUs. We will review relevant literature in thenext section to clarify different works that have been done. Based on the philosophy of cross-efficiency, this paper proposes a novel approach to rank DMUs by integrating with Shapley values from the perspective of a cooperative game. Specifically, we firstly give a new concept of characteristic function of DMUs, which satisfies the property of superadditivity. DMUs in a coalition are assumed to cooperate but to compete with each other outside the coalition. Following this idea, a solution is formulated to determine their Shapley values when DMUs adopt aggressive or benevolent strategies in DEA cooperative game.

The remainder of this paper is structured as follows: literature reviews are carried out in section 2. The preliminaries are presented in Section 3. In Section 4, we develop the Shapley value-based ranking method in DEA cooperative game. A case study concerning the evaluation of nine Chinese container ports is given in Section 5. The paper ends with some concluding remarks in Section 6.

\section{Literature review}

The idea of cross-evaluation was originally proposed by Sexton et al. (1986), where each DMU determines a set of weights, and accordingly, each one has multiple efficiencies whose average reflects its overall performance. This mechanism provides a more justifiable view to rank DMUs (Yang et al. 2013). Doyle and Green $(1994,1995)$ further developed two pioneering models, namely, the benevolent and aggressive secondary models to resolve the non-uniqueness of optimal weights. Since then, many additional researches have been conducted regarding the specification of alternative secondary goals that signify various 
An Integrated Approach Using Cross-Efficiency and Shapley Value in Performance Evaluation

modeling assumptions (Ertay and Ruan 2005; Bao et al. 2008; Liang et al. 2008; Wang and Chin 2010; Yu et al. 2010; Liu et al. 2017; Carrillo and Jorge, 2018).

With the popularity of game theory in decision evaluation, Banker (1980) first studied DEA from a non-cooperative game perspective and related CCR model with two persons zero-sum game. Liang et al. (2008) introduced the concept of game cross-efficiency, where DMUs are regarded as players, and cross- efficiency scores as their payoffs. By maximizing each one's cross-efficiency without deteriorating the others' efficiency scores, the optimal game cross- efficiency scores reach a Nash equilibrium point. Based on Liang et al.'s work, Wu et al. (2009b) presented a modified DEA game cross-efficiency model that allows variable returns to scale (VRS), and applied this model in six Olympic Games. Wu et al. (2009c) also established a bargaining game model to improve the traditional cross-efficiency evaluation, where the bargaining efficiency derived from this model is proved to be a Pareto solution for DMUs. Subsequently, Wu and Liang (2012) put forward a prioritization method using the game cross-efficiency under multi-criteria decision making environment. As for the appraisal of scientific journals, Li et al. (2016a) employed the CEE with assurance region under a game- theoretic framework.

As discussed above, CEE has been combined with a non-cooperative game in both theoretic and practical researches. There also exist some attempts to integrate cooperative game theory into the DEA framework. Nakabayashi and Tone (2006) handled the consensus-making problem via a cooperative game approach in DEA and discussed some properties of imputations in such DEA game. Jahanshahloo et al. (2006) analyzed the so-called Egoist's dilemma problem with interval data in the context of DEA cooperative game. Inspired by Nakabayashi and Tone (2006)'s work, $\mathrm{Wu}$ et al.(2009a) defined the characteristic function of a coalition and calculated DMUs' cross-efficiency scores via their Shapley values and associated weights. Later, Omrani et al. (2018) applied the approach in Wu et al.(2009a) to measure the transportation energy in 20 provinces in Iran. Lozano (2012) argued that DMUs can gain if they share information with each other, and constructed a model to compute $\tau$-value for DMUs in a coalition. Li et al. (2016b) compute the Shapley values based on the principle of fairness in a cooperative game and extend the method to a VRS case. Hinojosa et al. (2017) utilize Shapley value in two dual cooperative games for ranking efficient DMUs.

Despite the fact that different works have been done focusing on DEA from the view of cooperative game, the relation between cross-efficiency score and 
imputation of a DMU has not yet been deeply examined. As revealed by $\mathrm{Wu}$ et al.(2009a), there are some limitations for utilizing the average cross-efficiency measure for assessment. For instance, like the two different strategies, benevolent or aggressive formulation, so which one is more optimal for a DMU to adopt in peer evaluation? Besides, since Shapley value is a concept of one-point solution, it is natural to expect the efficiency scores in DEA cooperative game can be briefly written in the single-valued form.

\section{Preliminaries}

\subsection{CCR and CEE}

Assume there are $n \mathrm{DMU}_{j}(j=1,2, \ldots, n)$, and each DMU has $m$ inputs and $s$ outputs. The input and output values of $\mathrm{DMU}_{j}$ are represented by $x_{i j}(i=1,2, \ldots, m)$ and $y_{r j}(r=1,2, \ldots, s)$, respectively. For any evaluated $\mathrm{DMU}_{k}(k=1,2, \ldots, n)$, the relative efficiency can be measured by the following CCR model:

$$
\begin{aligned}
\max & \theta_{k k}=\sum_{r=1}^{s} u_{r k} y_{r k} \\
\text { s.t. } & \sum_{i=1}^{m} v_{i k} x_{i k}=1 \\
& \sum_{r=1}^{s} u_{r k} y_{r j}-\sum_{i=1}^{m} v_{i k} x_{i j} \leq 0, \quad j=1,2, \ldots, n \\
& u_{r k}, v_{i k} \geq 0, \quad r=1,2, \ldots, s, i=1,2, \ldots, m
\end{aligned}
$$

where $v_{i k}$ and $u_{r k}$ are the $r$ th input and output weights, respectively. For each

$\mathrm{DMU}_{k}$, we get a group of optimal weights $v_{i k}^{*}(i=1,2, \ldots, m)$ and $u_{r k}^{*}(r=1,2, \ldots, s)$; then,

$$
\theta_{k j}=\frac{\sum_{r=1}^{s} u_{r k}^{*} y_{r j}}{\sum_{i=1}^{m} v_{i k}^{*} x_{i j}}
$$

is viewed as the cross efficiency of $\mathrm{DMU}_{j}$ related to $\mathrm{DMU}_{k}$ via peer-evaluation. The cross-efficiency scores of $\operatorname{DMU}_{j}(j=1,2, \ldots, n)$ are then defined as the average of $\theta_{k j}(k=1,2, \ldots, n)$ :

$$
\theta_{j}=\frac{1}{n} \sum_{k=1}^{n} \theta_{k j}
$$


An Integrated Approach Using Cross-Efficiency and Shapley Value in Performance Evaluation

\subsection{Secondary goals}

The non-uniqueness of input/output weights impedes the use of CEE in practice. To overcome this problem, Doyle and Green (1994) suggest two secondary goals for a single DMU as follows,

$$
\begin{aligned}
\theta_{k j}^{\min } & =\min \sum_{r=1}^{s} u_{r k} y_{r j} \\
\text { s.t. } & \sum_{i=1}^{m} v_{i k} x_{i j}=1 \\
& \sum_{r=1}^{s} u_{r k} y_{r k}-\theta_{k k}^{*} \sum_{i=1}^{m} v_{i k} x_{i k}=0 \\
& \sum_{r=1}^{s} u_{r k} y_{r j}-\sum_{i=1}^{m} v_{i k} x_{i j} \leq 0, j=1,2, \ldots, n \\
& u_{r k}, v_{i k} \geq 0, \quad r=1,2, \ldots, s, i=1,2, \ldots, m
\end{aligned}
$$

and

$$
\begin{aligned}
\theta_{k j}^{\max } & =\max \sum_{r=1}^{s} u_{r k} y_{r j} \\
\text { s.t. } & \sum_{i=1}^{m} v_{i k} x_{i j}=1 \\
& \sum_{r=1}^{s} u_{r k} y_{r k}-\theta_{k k}^{*} \sum_{i=1}^{m} v_{i k} x_{i k}=0 \\
& \sum_{r=1}^{s} u_{r k} y_{r j}-\sum_{i=1}^{m} v_{i k} x_{i j} \leq 0, j=1,2, \ldots, n \\
& u_{r k}, v_{i k} \geq 0, \quad r=1,2, \ldots, s, i=1,2, \ldots, m
\end{aligned}
$$

Model (4) is regarded as the aggressive formulation for CEE, and its optimal objective value $\theta_{k j}^{\min }$ reflects the minimum cross-efficiency of $\mathrm{DMU}_{j}$ evaluated by $\mathrm{DMU}_{k}$. Analogously, model (5) is known as the benevolent formulation for CEE and its optimal objective value $\theta_{k j}^{\max }$ is the maximum cross-efficiency of $\mathrm{DMU}_{j}$ evaluated by $\mathrm{DMU}_{k}$. As a consequence, the $n \times n$ minimum/maximum crossefficiency matrix is generated for the $n$ DMUs:

$$
\theta^{\min }=\left[\begin{array}{cccc}
\theta_{11}^{\min } & \theta_{12}^{\min } & \cdots & \theta_{1 n}^{\min } \\
\theta_{21}^{\min } & \theta_{22}^{\min } & \cdots & \theta_{2 n}^{\min } \\
\vdots & \vdots & \cdots & \vdots \\
\theta_{n 1}^{\min } & \theta_{n 2}^{\min } & \cdots & \theta_{n n}^{\min }
\end{array}\right], \quad \theta^{\max }=\left[\begin{array}{cccc}
\theta_{11}^{\max } & \theta_{12}^{\max } & \cdots & \theta_{1 n}^{\max } \\
\theta_{21}^{\max } & \theta_{22}^{\max } & \cdots & \theta_{2 n}^{\max } \\
\vdots & \vdots & \cdots & \vdots \\
\theta_{n 1}^{\max } & \theta_{n 2}^{\max } & \cdots & \theta_{n n}^{\max }
\end{array}\right]
$$




\section{Methodology}

This section develops an integrated approach to evaluate DMUs based on the Shapley value. We presume a DMU in a coalition would be kind to his allies thus adopts a benevolent strategy in peer-evaluation. On the contrary, a DMU would be confrontational to the other DMUs who are not in the same coalition so an aggressive strategy is applied in peer-evaluation.

\subsection{Shapley values}

Let $N$ denote a finite set of players, and $S \subset N$ be a coalition. Assume $|N|=n$, a characteristic function $v: 2^{N} \rightarrow R$ associates a real number (the payoff) of $N$. The idea behind Shapley value (Shapley 1953) is that each player should be allocated an average of his marginal contribution to the coalition, and the Shapley value $\varphi_{j}(v)$ of player $j$ is,

$$
\varphi_{j}(v)=\sum_{S \subseteq N} \frac{(|S|-1) !(n-|S|) !}{n !}(v(S)-v(S \backslash\{j\}))
$$

where $|S|$ is the cardinality of $S$. The payoffs of all players are expressed by a vector $\varphi(N, v)=\left(\varphi_{j}(v)\right)_{j \in N}$. It is well-known that Shapley value is an unique solution concept that satisfies the following properties: (1) Efficiency: $\sum_{j \in N} \varphi_{j}(v)=v(N)$; (2) Null Player: for each null player $j \in N$, then $\varphi_{j}(v)=0$; (3) Symmetry: for each pair $(k, l)$ of symmetric players, $\varphi_{k}(v)=\varphi_{l}(v)$; (4) Additivity: for each pair $v$ and $w$ of cooperative games, then $\varphi(v+w)=\varphi(v)+\varphi(w)$.

\subsection{Shapley values in DEA cooperative game}

Under a DEA cooperative game situation, it is advisable for a DMU to discriminate against other DMUs who come from different coalitions. Bear this assumption in mind, for a $\mathrm{DMU}_{j} \in S(j=1,2, \ldots, n), \mathrm{DMU}_{j}$ should take a benevolent strategy in evaluating the other DMUs who insides $S$ in order to maximize the coalitional payoff. On the other hand, it is reasonable that $\mathrm{DMU}_{j}$ be antagonistic to the other DMUs who outside $S$ by using the aggressive strategy in DEA game.

During CEE context, it means $\mathrm{DMU}_{j}$ intends to adopt the benevolent formulation in peer-evaluated with $\mathrm{DMU}_{k} \in S(k \neq j)$ by maximizing his cross-efficiency $\theta_{j k}$, whereas uses the aggressive formulation in peer-evaluated with $\mathrm{DMU}_{l} \notin S(l \neq j)$ by minimizing his cross-efficiency $\theta_{j l}$. From the above analysis, the characteristic function of coalition $S$ can be defined as follows: 
An Integrated Approach Using Cross-Efficiency and Shapley Value in Performance Evaluation

Definition 1. Let $v(S)$ be the characteristic function of $S$ with $\mathrm{DMU}_{j}, j=1$, $2, \ldots, n$, then

$$
v(S)=\frac{1}{n} \sum_{j \in S}\left(\sum_{k \in S} \theta_{k j}^{\max }+\sum_{l \notin S} \theta_{l j}^{\min }\right)
$$

where $\theta_{k j}^{\max }$ and $\theta_{l j}^{\min }$ are the maximum and minimum cross-efficiencies of $\mathrm{DMU}_{j}$ peer-evaluated by $\mathrm{DMU}_{k}$ and $\mathrm{DMU}_{l}$, respectively.

Theorem 1. The characteristic function $v(S)$ satisfies the superadditivity.

Proof. Let $S_{1}, S_{2} \subset N$ be two coalitions where $S_{1} \cap S_{2}=\varnothing$. For brevity we denote,

$$
\left\{\begin{array}{l}
v(S)=\sum_{j \in S} \Delta_{j}^{S} \\
\Delta_{j}^{S}=\frac{1}{n}\left(\sum_{k \in S} \theta_{k j}^{\max }+\sum_{l \notin S} \theta_{l j}^{\min }\right)
\end{array}\right.
$$

From Eq.(8), we have

$$
\begin{gathered}
v\left(S_{1} \cup S_{2}\right)=\sum_{j \in S_{1} \cup S_{2}} \Delta_{j}^{S_{1} \cup S_{2}} \\
v\left(S_{1}\right)+v\left(S_{2}\right)=\sum_{k \in S_{1}} \Delta_{k}^{S_{1}}+\sum_{l \in S_{2}} \Delta_{l}^{S_{2}}
\end{gathered}
$$

Since $S_{1} \cap S_{2}=\varnothing$, Eq.(9) can be equivalently rewritten as,

$$
v\left(S_{1} \cup S_{2}\right)=\sum_{k \in S_{1}} \Delta_{k}^{S_{1} \cup S_{2}}+\sum_{l \in S_{2}} \Delta_{l}^{S_{1} \cup S_{2}}
$$

Due to the fact that $S_{1}, S_{2} \subset S_{1} \cup S_{2}$, and $\theta_{k j}^{\min } \leq \theta_{k j}^{\max }, \theta_{l j}^{\min } \leq \theta_{l j}^{\max }$;Thus, $\Delta_{k}^{S_{1} \cup S_{2}}$ $\geq \Delta_{k}^{S_{1}}$, and $\Delta_{l}^{S_{1} \cup S_{2}} \geq \Delta_{l}^{S_{1}}$. Therefore, $v\left(S_{1} \cup S_{2}\right) \geq v\left(S_{1}\right)+v\left(S_{2}\right)$. This completes the proof of Theorem 1 .

Theorem 1indicates a DMU has an incentive to cooperate with other DMUs since cooperation generates extra gains for them. That is to say, a single DMU only obtains the payoff corresponding to his cross-efficiency; while the grand coalition $N$ acquires the payoff of the sum of maximum cross-efficiencies of all DMUs, i.e., $v(N)=\frac{1}{n} \sum_{j \in N} \sum_{k \in N} \theta_{k j}^{\max }$.

When a coalition is formed, a problem arises that how to assign the overall profit in a reasonable way? As discussed before, Shapley values are one of the most important solutions for a coalitional game. Based on the definition 1, we derive the Shapley values in DEA cooperative game within cross-efficiency scores by the following theorem. 
Theorem 2. Let $\varphi_{j}(v)$ be the Shapley value of $\mathrm{DMU}_{j}$ in DEA cooperative game $(N, v)$, then

$$
\varphi_{j}(v)=\frac{1}{2}\left(\theta_{j}^{\max }+\theta_{j}^{\min }\right)+\frac{1}{2 n} \sum_{k=1}^{n}\left(\theta_{j k}^{\max }-\theta_{j k}^{\min }\right)
$$

where $\theta_{j}^{\max }$ and $\theta_{j}^{\min }$ are the maximum and minimum cross-efficiency scores of $\mathrm{DMU}_{j}$ calculated by Eq.(3); $\theta_{j k}^{\min }$ and $\theta_{j k}^{\max }$ are the optimal cross-efficiencies of $\operatorname{DMU}_{k}(k=1,2, \ldots, n, k \neq j)$ related to $\mathrm{DMU}_{j}$ by models (4) and (5), respectively.

Proof. Assume a $\mathrm{DMU}_{j} \in S(j=1,2, \ldots, n)$, according to Definition 1 , we have

$$
\left\{\begin{array}{l}
v(S)=\sum_{k \in S} \Delta_{k}^{S}=\Delta_{j}^{S}+\sum_{k \in S /\{j\}} \Delta_{k}^{S} \\
v(S /\{j\})=\sum_{k \in S /\{j\}} \Delta_{k}^{S /\{j\}}
\end{array}\right.
$$

So the marginal contribution of $\mathrm{DMU}_{j}$ to the coalition $S$ is,

$$
v(S)-v(S /\{j\})=\Delta_{j}^{S}+\sum_{k \in S /\{j\}}\left(\Delta_{k}^{S}-\Delta_{k}^{S /\{j\}}\right)
$$

For any $k \in S /\{j\}$, according to Eq.(8) it follows that

$$
\Delta_{k}^{S}-\Delta_{k}^{S /\{j\}}=\frac{1}{n}\left(\theta_{j k}^{\max }-\theta_{j k}^{\min }\right)
$$

Thus, Eq.(14) can be rewritten as

$$
v(S)-v(S /\{j\})=\frac{1}{n}\left[\theta_{j j}+\sum_{k \in S /\{j\}}\left(\theta_{k j}^{\max }+\theta_{j k}^{\max }-\theta_{j k}^{\min }\right)+\sum_{l \notin S} \theta_{k l}^{\min }\right]
$$

Substituting Eq.(15) into Eq. (6) gives the Shapley value of $\mathrm{DMU}_{j}$ as,

$$
\varphi_{j}(v)=\sum_{j \in S, S \subseteq N} \frac{\beta}{n}\left[\theta_{j j}+\sum_{k \in S /\{j\}}\left(\theta_{k j}^{\max }+\theta_{j k}^{\max }-\theta_{j k}^{\min }\right)+\sum_{l \notin S} \theta_{k l}^{\min }\right]
$$

where $\beta=\frac{(|S|-1) !(n-|S|) !}{n !}$. Eq.(16) can be equivalently expressed as,

$$
\varphi_{j}(v)=\phi \theta_{j j}+\sum_{k=1, k \neq j}^{n}\left[\varphi_{k}\left(\theta_{k j}^{\max }+\theta_{j k}^{\max }-\theta_{j k}^{\min }\right)+\gamma_{k} \theta_{k j}^{\min }\right]
$$

where the different coefficients in Eq. (17) are listed below,

$$
\left\{\phi=\sum_{\substack{j \in S, S \subseteq N}} \frac{\beta}{n}, \quad \varphi_{k}=\sum_{\substack{j \in S, k \in S \\ j \neq k, S \subseteq N}} \frac{\beta}{n}, \quad \gamma_{k}=\sum_{\substack{j \in S, k \notin S \\ S \subseteq N}} \frac{\beta}{n}\right\}
$$

To derive the mathematical results of these coefficients, let $|S|=t$, for a given $\mathrm{DMU}_{j}$, the number of coalitions that satisfies: (1) containing the $\mathrm{DMU}_{j} ;$ (2) 
An Integrated Approach Using Cross-Efficiency and Shapley Value in Performance Evaluation

cardinality is equal to $t$, is calculated as $C_{n-1}^{t-1}=\frac{(n-1) !}{(t-1) !(n-t) !}$. Thus the parameter $\phi$ can be simplified as,

$$
\phi=\sum_{t=1}^{n} C_{n-1}^{t-1} \frac{(t-1) !(n-t) !}{n ! n}=\frac{1}{n}
$$

As to $\varphi$, for $\mathrm{DMU}_{j}$ and $\mathrm{DMU}_{k}$, the number of coalitions that satisfies: (1) containing both of them; (2) the cardinality is equal to $t(t \geq 2)$, can be calculated as $C_{n-1}^{t-2}=\frac{(n-2) !}{(t-2) !(n-t) !}$, following that $\phi=\sum_{t=2}^{n} C_{n-2}^{t-2} \frac{(t-1) !(n-t) !}{n ! n}=\frac{1}{2 n}$. The last coefficient $\gamma$ can be obtained in a similar way, which the result is $\gamma=\frac{1}{2 n}$.

In what follows, we substitute these coefficients into Eq. (17) yields,

$$
\varphi_{j}(v)=\frac{1}{n} \theta_{j j}+\frac{1}{2 n} \sum_{k=1, k \neq j}^{n}\left(\theta_{k j}^{\max }+\theta_{j k}^{\max }-\theta_{j k}^{\min }+\theta_{k j}^{\min }\right)
$$

Considering $\theta_{j j}=\theta_{j j}^{\min }=\theta_{j j}^{\max }$, the above equation becomes,

$$
\begin{aligned}
\varphi_{j}(v) & =\frac{1}{2 n} \sum_{k=1}^{n}\left(\theta_{k j}^{\max }+\theta_{k j}^{\min }\right)+\frac{1}{2 n} \sum_{k=1, k \neq j}^{n}\left(\theta_{j k}^{\max }-\theta_{j k}^{\min }\right) \\
& =\frac{1}{2}\left(\theta_{j}^{\max }+\theta_{j}^{\min }\right)+\frac{1}{2 n} \sum_{k=1}^{n}\left(\theta_{j k}^{\max }-\theta_{j k}^{\min }\right)
\end{aligned}
$$

This completes the proof of Theorem 2 .

\section{Case study}

\subsection{Problem and calculations}

As a key pivot in global logistical system, Container ports play a vital role in marine transportation as over $80 \%$ of global trade is seaborne. Operational efficiency evaluation is essential in port management. Effective prioritization of ports' performance not only helps the port stakeholders to improve its marketing strategies, but also provide a theoretical basis for the local government to formulate relevant policies (Wu and Liang, 2009).

Since 2016, China home to 7 of the top 10 ports in the world based on transport and throughput capacity. These port terminals are crucial elements in Belt and Road Initiative (BRI), Chinese greatest international policy initiative. In this study, we select nine ports in China (Ningbo, Shanghai, Tianjin, Dalian, Yingkou, Nanjing, Xiamen, Chongqing and Zhuhai ports) as DMUs( $\left.\mathrm{DMU}_{1} \sim \mathrm{DMU}_{9}\right)$ and rank them according to their productive efficiencies.

Based on the existing researches, the input factors of container ports are mainly concerning the aspects of capital, goods and labor (Ren et al. 2018). Seven 
Yang Lin,Wen-li Liu, Ying-Ming Wang

criteria including deep-water berth $\left(x_{1}\right)$, coastline $\left(x_{2}\right)$, property $\left(x_{3}\right)$, equipment asset $\left(x_{4}\right)$, storeroom area $\left(x_{5}\right)$, operating cost $\left(x_{6}\right)$ and number of employee $\left(x_{7}\right)$ are chosen as inputs, and two criteria of throughput $\left(y_{1}\right)$ and profit $\left(y_{2}\right)$ are chosen as outputs, which are shown in Table 1. The statistical data are collected from Lai et al.(2018).

Table 1. The input and output data of nine ports

\begin{tabular}{|c|c|c|c|c|c|c|c|c|c|}
\hline & \multicolumn{9}{|c|}{ Ningbo Shanghai Tianjin Dalian Yingkou Nanjing Xiamen Chongqing Zhuhai } \\
\hline Berth(units) & 615 & 608 & 162 & 240 & 87 & 69 & 173 & 191 & 153 \\
\hline Coastline (km) & 14.7 & 126 & 36 & 42.6 & 18.2 & 8.6 & 28.2 & 15.3 & 17 \\
\hline *Property & 581.5 & 1168 & 323 & 319 & 165 & 46.9 & 74 & 76.7 & 57 \\
\hline *Equipment asset & 53.9 & 55.6 & 25.3 & 10.9 & 1.6 & 0.1 & 3.6 & 6.7 & 13.3 \\
\hline Storeroom $\left(\mathbf{h m}^{2}\right)$ & 878 & 885 & 1118 & 529 & 735 & 288 & 571 & 151 & 288 \\
\hline *Operating cost & 140.3 & 244.2 & 117.8 & 122.8 & 22.1 & 1.38 & 87.9 & 21.2 & 16.9 \\
\hline Employee( $\left(10^{3}\right.$ units $)$ & s) 1.17 & 1.83 & 0.76 & 0.68 & 0.49 & 0.07 & 0.39 & 0.22 & 0.2 \\
\hline $\begin{array}{l}\text { Throughput } \\
\left(10^{4} \text { TEU) }\right.\end{array}$ & 9.18 & 7.0 & 5.5 & 4.29 & 3.47 & 2.17 & 2.09 & 1.72 & 0.9 \\
\hline *Profit & 22.99 & 69.39 & 12.64 & 5.31 & 3.53 & 0.85 & 2.07 & 0.78 & 1.04 \\
\hline
\end{tabular}

*Monetary unit is 100 million RMB

Firstly, the CCR-efficiencies of these DMUs are calculated according to model (1), which are listed in Table 2. Apparently, CCR model fails to discriminate these DMUs as six DMUs are evaluated as CCR-efficient. Subsequently, we conduct a peer-evaluation of the 9 DMUs by using models (4) and (5), and the results are shown in Tables 3-4.Finally, the Shapley values of DMUs via Eq. (12) are exhibited in Table 5. Based on the obtained Shapley values, all DMUs (ports) are fully ranked where Nanjing port ( $\mathrm{DMU}_{6}$ ) was recognized as the most efficient one, followed by Shanghai port ( $\mathrm{DMU}_{2}$ ), Ningbo port ( $\mathrm{DMU}_{1}$ ) and so on. It is observed that Zhuhai port $\left(\mathrm{DMU}_{9}\right)$ was regarded as the least efficient one. The outcome of recognizing Nanjing port as the most efficient one may sound reasonable, because it has the fewest employees, the least equipment asset, and the shortest coastline of inputs. The Zhuhai port, however, has the lowest output of throughput capability among the nine ports.

Table 2. CCR-efficiencies of the 9 ports

\begin{tabular}{lccccccccc}
\hline $\begin{array}{l}\text { DMU } \\
\text { (Port) }\end{array}$ & $\mathbf{1}$ & $\mathbf{2}$ & $\mathbf{3}$ & $\mathbf{4}$ & $\mathbf{5}$ & $\mathbf{6}$ & $\mathbf{7}$ & $\mathbf{8}$ & $\mathbf{9}$ \\
\hline $\begin{array}{l}\text { CCR- } \\
\text { efficiency }\end{array}$ & 1.00 & 1.00 & 1.00 & 0.9435 & 1.00 & 1.00 & 0.8695 & 1.00 & 0.5234 \\
\hline
\end{tabular}


An Integrated Approach Using Cross-Efficiency and Shapley Value in Performance Evaluation

Table 3. Minimum cross-efficiency matrix

\begin{tabular}{|c|c|c|c|c|c|c|c|c|c|}
\hline \multirow{2}{*}{$\begin{array}{l}\text { DMU } \\
\text { (Port) }\end{array}$} & \multicolumn{9}{|c|}{ Target DMU } \\
\hline & 1 & 2 & 3 & 4 & 5 & 7 & 8 & 9 & \\
\hline 1 & 1.0000 & 0.3275 & 0.4502 & 0.997 & 0.2007 & 0.0078 & 0.8499 & 0.7972 & 0.8499 \\
\hline 2 & 0.0889 & 1.0000 & 0.6041 & 0.9976 & 0.1509 & 0.0058 & 0.998 & 0.3866 & 0.9996 \\
\hline 3 & 0.2245 & 0.1442 & 1.0000 & 0.6242 & 0.2886 & 0.0101 & 0.8637 & 0.4319 & 0.8635 \\
\hline 4 & 0.0808 & 0.128 & 0.3836 & 0.9435 & 0.2583 & 0.0182 & 0.4642 & 0.5793 & 0.4641 \\
\hline 5 & 0.124 & 0.0612 & 0.7896 & 0.6522 & 1.0000 & 0.0999 & 0.6559 & 0.4145 & 0.6558 \\
\hline 6 & 0.0631 & 0.0376 & 0.4743 & 0.9998 & 0.5238 & 1.0000 & 0.9999 & 0.6597 & 0.9997 \\
\hline 7 & 0.0469 & 0.0462 & 0.2367 & 0.4737 & 0.2096 & 0.0151 & 0.8695 & 0.3109 & 0.8688 \\
\hline 8 & 0.0326 & 0.0358 & 0.1400 & 0.9993 & 0.0597 & 0.0118 & 0.5058 & 1.0000 & 0.5057 \\
\hline 9 & 0.0391 & 0.0461 & 0.1226 & 0.3098 & 0.0439 & 0.0031 & 0.5234 & 0.2706 & 0.52340 \\
\hline
\end{tabular}

Table 4. Maximum cross-efficiency matrix

\begin{tabular}{|c|c|c|c|c|c|c|c|c|c|}
\hline \multirow{2}{*}{$\begin{array}{l}\text { DMU } \\
\text { (Port) }\end{array}$} & \multicolumn{9}{|c|}{ Target DMU } \\
\hline & 1 & 2 & 3 & 4 & 6 & 7 & 8 & 9 & \\
\hline 1 & 1.0000 & 1.0000 & 1.0000 & 1.0000 & 1.0000 & 1.0000 & 0.8499 & 1.0000 & 0.8499 \\
\hline 2 & 1.0000 & 1.0000 & 1.0000 & 1.0000 & 1.0000 & 1.0000 & 1.0000 & 1.0000 & 1.0000 \\
\hline 3 & 1.0000 & 1.0000 & 1.0000 & 0.6245 & 1.0000 & 1.0000 & 0.8637 & 0.6801 & 0.8637 \\
\hline 4 & 0.9434 & 0.9435 & 0.7768 & 0.9435 & 0.7294 & 0.9435 & 0.4642 & 0.9435 & 0.4643 \\
\hline 5 & 1.0000 & 1.0000 & 1.0000 & 0.6524 & 1.0000 & 1.0000 & 0.656 & 0.6523 & 0.656 \\
\hline 6 & 1.0000 & 1.0000 & 1.0000 & 1.0000 & 1.0000 & 1.0000 & 1.0000 & 1.0000 & 1.0000 \\
\hline 7 & 0.6661 & 0.8695 & 0.6107 & 0.4738 & 0.5135 & 0.8695 & 0.8695 & 0.5504 & 0.8695 \\
\hline 8 & 1.0000 & 1.0000 & 0.4535 & 1.0000 & 0.3896 & 1.0000 & 0.5058 & 1.0000 & 0.5057 \\
\hline 9 & 0.4602 & 0.5234 & 0.3323 & 0.3101 & 0.2561 & 0.5234 & 0.5234 & 0.4313 & 0.5234 \\
\hline
\end{tabular}

Table 5. Shapley values of the 9 ports

\begin{tabular}{lcccccccccc}
\hline DMU (Port) & $\mathbf{1}$ & $\mathbf{2}$ & $\mathbf{3}$ & $\mathbf{4}$ & $\mathbf{5}$ & $\mathbf{6}$ & $\mathbf{7}$ & $\mathbf{8}$ & $\mathbf{9}$ \\
\hline $\begin{array}{c}\text { Shapley } \\
\text { value }\end{array}$ & 1.142 & 1.152 & 0.859 & 0.582 & 0.901 & 1.218 & 0.521 & 0.697 & 0.320 \\
\hline Rank & 3 & 2 & 5 & 7 & 4 & 1 & 8 & 6 & 9 & \\
\hline
\end{tabular}


Yang Lin,Wen-li Liu, Ying-Ming Wang

\subsection{Comparison and Discussion}

The Shapley value $\varphi_{j}(v)$ of $\mathrm{DMU}_{j}$ consists of two parts, the first part $\frac{1}{2}\left(\theta_{j}^{\max }+\theta_{j}^{\min }\right)$ is the average of its maximum and minimum cross-efficiency scores, and the second part $\frac{1}{2 n} \sum_{k=1}^{n}\left(\theta_{j k}^{\max }-\theta_{j k}^{\min }\right)$ approximates to the average of differences between themaximum and minimum cross-efficiencies evaluated by $\mathrm{DMU}_{k}(k=1,2, \ldots, n)$. On one hand, the Shapley value of a DMU is influenced by its corresponding maximum and minimum cross-efficiencies; On the other hand, a higher difference value between the maximum and minimum cross-efficiencies signifies a greater imputation to a DMU. Particularly, if the difference of $\mathrm{DMU}_{j}$ is equivalent to 0 , i.e., $\theta_{j k}^{\min }$ derived by model (4) is equal to $\theta_{j k}^{\max }$ derived by model (5), $k=1,2, \ldots, n$, then there is no extra gain brought by $\mathrm{DMU}_{j}$ into the coalition in such case.

Notice that in this example, the sum of the maximum cross-efficiencies of all DMUs equals to the sum of all the Shapley values. In other words, the imputation derived by Theorem 2 satisfies the efficiency property, where the sum total that all DMUs expect to gain is $v(N)$, the worth of the grand coalition.

To conduct a comparative analysis, we further evaluate the DMUs by Wu et al.(2009a)'s model, the aggressive and benevolent formulation and the proposed method. The results are depicted in Table 6 .

From Table 6, we found the four various methods completely rank these DMUs, where $\mathrm{DMU}_{6}$ is ranked first and $\mathrm{DMU}_{9}$ ranked at the bottom. It is observed that the results obtained by aggressive and benevolent formulations are more close to that of the proposed approach. The model in Wu et al. (2009a) is also from a cooperative game viewpoint, where Shapley values are calculated to determine the cross-efficiency scores of DMUs. In their model, $\mathrm{DMU}_{5}$ (Yingkou) and $\mathrm{DMU}_{2}$ (Shanghai) were ranked in second and fourth place, respectively, whereas they are in reverse positions by the developed method. It is mainly because the two method works in different mechanisms where our method consider the average contribution of each DMU, yet Wu et al.'s method is based on the individual and grand coalition rationalities of all DMUs. It is also observed that the results from both aggressive and benevolent formulation support our ranking conclusion. 
An Integrated Approach Using Cross-Efficiency and Shapley Value in Performance Evaluation

Table 6. The efficiency results of 9 DMUs

\begin{tabular}{ccccc}
\hline DMU & $\begin{array}{c}\text { Wu et al.'s } \\
\text { model }\end{array}$ & $\begin{array}{c}\text { Aggressive } \\
\text { formulation }\end{array}$ & $\begin{array}{c}\text { Benevolent } \\
\text { formulation }\end{array}$ & $\begin{array}{c}\text { The proposed } \\
\text { method }\end{array}$ \\
\hline $\mathbf{1}$ & $0.2930(3)$ & $0.6089(2)$ & $0.9666(3)$ & $1.1417(3)$ \\
\hline $\mathbf{2}$ & $0.2182(4)$ & $0.5813(3)$ & $1.0000(1)$ & $1.1523(2)$ \\
\hline $\mathbf{3}$ & $0.1512(5)$ & $0.4945(5)$ & $0.8924(4)$ & $0.8586(5)$ \\
\hline $\mathbf{4}$ & $0.1186(6)$ & $0.3689(7)$ & $0.7947(6)$ & $0.5822(7)$ \\
\hline $\mathbf{5}$ & $0.3160(2)$ & $0.4948(4)$ & $0.8463(5)$ & $0.9013(4)$ \\
\hline $\mathbf{6}$ & $0.3758(1)$ & $0.6398(1)$ & $1.0000(1)$ & $1.2179(1)$ \\
\hline $\mathbf{7}$ & $0.0853(8)$ & $0.3419(8)$ & $0.6992(8)$ & $0.5207(8)$ \\
\hline $\mathbf{8}$ & $0.1124(7)$ & $0.3656(6)$ & $0.7616(7)$ & $0.6973(6)$ \\
\hline $\mathbf{9}$ & $0.0656(9)$ & $0.2091(9)$ & $0.4315(9)$ & $0.3204(9)$ \\
\hline
\end{tabular}

For a better comparison, we use the Spearman rank-order correlation (Spearman, 1904) to analyze the similarity among these efficiency scores. The results were presented in Table 7.

Table 7. Spearman Rank-order of different methods

\begin{tabular}{cccccc}
\hline Approach & $\begin{array}{c}\text { CCR } \\
\text { model }\end{array}$ & $\begin{array}{c}\text { Aggressive } \\
\text { formulation }\end{array}$ & $\begin{array}{c}\text { Benevolent } \\
\text { formulation }\end{array}$ & $\begin{array}{c}\text { Wu et al's } \\
\text { model }\end{array}$ & $\begin{array}{c}\text { The proposed } \\
\text { method }\end{array}$ \\
\hline CCR model & 1.000 & 0.983 & 0.998 & 0.958 & 0.996 \\
$\begin{array}{c}\text { Aggressive } \\
\text { formulation }\end{array}$ & & 1.000 & 0.990 & 0.994 & 0.988 \\
$\begin{array}{c}\text { Benevolent } \\
\text { formulation } \\
\text { Wu et al's } \\
\text { model }\end{array}$ & & & 1.000 & 0.969 & 0.998 \\
$\begin{array}{c}\text { The proposed } \\
\text { method }\end{array}$ & & & & 1.000 & 0.967 \\
\hline
\end{tabular}

From the last column of Table 7, it is found that the proposed method is most correlated with the benevolent formulation and their correlation coefficient is as high as 0.998 . Besides, the coefficient is only 0.967 of our developed method related with Wu et al. (2009a)'s method since they have different principles as discussed before.

\section{Conclusions}

Cross-efficiency evaluation is a popular technique for comparing DMUs as it consumes both self-evaluation and peer-evaluation information. In this paper, a novel method based on Cross-efficiency and Shapley value has been developed to rank DMUs. The key features of the proposed method can be summarized as follows: 
Yang Lin,Wen-li Liu, Ying-Ming Wang

(1) we define a new characteristic function of coalitions for a DEA cooperative game;

(2) we present a brief formulation to derive DMUs' imputations by utilizing their cross-efficiency scores; (3) a full ranking of DMUs can be achieved according to the imputations in terms of Shapley values. Particularly, we prove the Shapley values can be simply expressed by their corresponding minimum and maximum cross-efficiency scores. To verify the developed method, an empirical example about evaluation of nine container ports in China has been conducted. In comparison with the existing approaches, the proposed method has a clearer programming mechanism and acceptable computational cost since complex modeling can be avoided. Although this method provides a flexible approach to analyze the prioritization of DMUs, incomplete or uncertain information are common in decision evaluation and cooperative game (Lin and Wang 2019; Li and Ye, 2018). Hence, future endeavors are needed to extend the current study with uncertain data.

\section{ACKNOWLEDGMENTS}

The authors would like to express their sincere thanks to anonymous referees and editors, which have helped to improve the paper. This work was supported by the National Social Science Foundation of China (19BGL092).

\section{REFERENCES}

[1] Charnes, A., Cooper, W. W. and Rhodes, E. (1978), Measuring the Efficiency of Decision Making Units. European Journal of Operational Research, 2(6), 429-444;

[2] Wu, J., Liang, L. and Yang, F. (2009a), Determination of the Weights for the Ultimate Cross Efficiency Using Shapley Value in Cooperative Game. Expert Systems with Applications, 36(1), 872-876;

[3] Sexton TR, Silkman RH and Hogan A.J. (1986), Data Envelopment Analysis: Critique and Extensions. In: Silkman RH (ed). Measuring Efficiency: An Assessment of Data Envelopment Analysis. Jossey-Bass: San Francisco, CA;

[4] Wang, Y. M., Chin, K. S. and Luo, Y. (2011), Cross-efficiency Evaluation Based on Ideal and Anti-ideal Decision Making Units. Expert systems with applications, 38(8), 10312-10319;

[5] Wu, J., Chu, J., Sun, J. and Zhu, Q. (2016), DEA Cross-efficiency Evaluation Based on Pareto Improvement. European Journal of Operational Research, 248(2), 571-579;

[6] Liang, L., Wu, J., Cook, W. D. and Zhu, J. (2008), The DEA Game Cross-efficiency Model and its Nash Equilibrium. Operations Research, 56(5), 1278-1288;

[7] Wang, Y. M. and Chin, K. S. (2010), A Neutral DEA Model for Cross-efficiency 
An Integrated Approach Using Cross-Efficiency and Shapley Value in Performance Evaluation

Evaluation and its Extension. Expert Systems with Applications, 37(5), 3666-3675;

[8] Wu, J., Sun, J. and Liang, L. (2012), Cross Efficiency Evaluation Method Based on

Weight-balanced Data Envelopment Analysis Model. Computers and Industrial

Engineering, 63(2), 513-519;

[9] Yang, G. L., Yang, J. B., Liu, W. B. and Li, X. X. (2013), Cross-efficiency

Aggregation in DEA Models Using the Evidential-reasoning Approach. European Journal of Operational Research, 231(2), 393-404;

[10] Doyle, J. and Green, R. (1994), Efficiency and Cross-efficiency in DEA: Derivations, Meanings and Uses. Journal of the Operations Research Society, 45, 567-578;

[11] Doyle, J. and Green, R. (1995), Cross-evaluation in DEA: Improving Discrimination among DMUs. INFOR: Information Systems and Operational Research,33(3): 205-222;

[12] Ertay, T. and Ruan, D. (2005), Data Envelopment Analysis Based Decision Model for Optimal Operator Allocation in CMS. European Journal of Operational Research, 164(3), 800-810;

[13] Bao, C. P., Chen, T. H. and Chang, S. Y. (2008), Slack-based Ranking Method: An Interpretation to the Cross-Efficiency Method in DEA. Journal of the Operational Research Society, 59(6), 860-862;

[14]Yu, M. M., Ting, S. C. and Chen, M. C. (2010), Evaluating the Cross-efficiency of Information Sharing in Supply Chains. Expert Systems with Applications, 37(4),

2891-2897;

[15] Liu, W., Wang, Y. M. and Lv, S. (2017), An Aggressive Game Cross-efficiency Evaluation in Data Envelopment Analysis. Annals of Operations Research, 259(1-2), 241-258;

[16] Carrillo, M. and Jorge, J. M. (2018), An Alternative Neutral Approach for Cross-efficiency Evaluation. Computers and Industrial Engineering, 120, 137-145;

[17] Banker, R. D. (1980), A Game Theoretic Approach to Measuring Efficiency.

European Journal of Operational Research, 5(4), 262-266;

[18] Wu, J., Liang, L. and Chen, Y. (2009b), DEA Game Cross-efficiency Approach to Olympic Rankings. Omega, 37(4), 909-918;

[19] Wu, J., Liang, L., Yang, F. and Yan, H. (2009c), Bargaining Game Model in the Evaluation of Decision Making Units. Expert Systems with Applications, 36(3), 4357-4362; [20] Wu, J. and Liang, L. (2012), A Multiple Criteria Ranking Method Based on Game Cross-evaluation Approach. Annals of Operations Research, 197(1), 191-200;

[21] Li L., Huang, H. J. and Wang, S. Y. (2016), Academic Journal Evaluation Based On DEA/AR Game Cross Efficiency Method. Journal of management sciences in China, 
Yang Lin, Wen-li Liu, Ying-Ming Wang

19(4),118-126;

[22] Nakabayashi, K. and Tone, K. (2006), Egoist's Dilemma: A DEA game. Omega, 34(2), 135-148;

[23] Jahanshahloo, G. R., Lotfi, F. H. and Sohraiee, S. (2006), Egoist's Dilemma with Interval Data. Applied Mathematics and Computation, 183(1), 94- 105;

[24] Lozano, S. (2012), Information Sharing in DEA: A Cooperative Game Theory Approach. European Journal of Operational Research, 222(3), 558-565;

[25] Omrani, H., Shafaat, K. and Alizadeh, A. (2018), Integrated Data Envelopment Analysis and Cooperative Game for Evaluating Energy Efficiency of Transportation Sector: A Case of Iran. Annals of Operations Research, 374(1-2), 471-499;

[26] Shapley, L. S. (1953), A Value for n-person Games. Contributions to the Theory of Games, 2(28), 307-317;

[27] Wu, J. and Liang, L. (2009), Performances and Benchmarks of Container Ports Using Data Envelopment Analysis. International Journal of Shipping and Transport Logistics, 1(3), 295-310;

[28] Ren, J., Dong, L. and Sun, L. (2018), Competitiveness Prioritization of Container Ports in Asia under the Background of China's Belt and Road Initiative. Transport Reviews, 38(4), 436-456;

[29] Lai, C.S., Lu, J. and Li, X. G. (2018), Port Production Efficiency Research Based on Two-Stage DEA Game Cross Efficiency Model. Journal of Shanghai Maritime University. 39(1), 52-59;

[30] Spearman, C. (1904), The Proof and Measurement of Association between two Things. American journal of Psychology, 15(1), 72-101;

[31] Lin, Y. and Wang, Y. M. (2019),Prioritization of Hesitant Multiplicative Preference Relations Based on Data Envelopment Analysis for Group Decision Making. Neural Computing and Applications, 31(2): 437-447.

[32] Li, D. F. and Ye, Y. F. (2018), An Approach to Computing Interval-valued Egalitarian Shapley Values of Interval-valued Cooperative Games with Coalition Monotonicity-like. Economic Computation and Economic Cybernetics Studies and Research; ASE Publishing, 52(3):73-84. 